\title{
Os processos de produção de conhecimentos e pesquisa na educação popular e saúde $^{1}$
}

Sonia Acioli ${ }^{2}$, José Ivo dos Santos Pedrosa ${ }^{3}$

\begin{abstract}
Resumo
Nessa reflexão defendemos um modo de pensar e fazer a prática pedagógica situado na luta histórica contra as várias formas de opressão e o não reconhecimento dos diversos saberes, em especial, os saberes populares e tradicionais. E, a identificação de caminhos possíveis na articulação entre práticas pedagógicas na perspectiva da educação popular e saúde (EPS) e processos de produção de conhecimentos e pesquisa que considerem os vários olhares e sentidos presentes e seu compromisso com as lutas por um bem viver. Por isso, para além de falarmos de métodos e metodologias, reconhecemos a necessidade de articular nossas práticas pedagógicas e políticas de EPS a práticas de pesquisa que fortaleçam a EPS como campo de ação e luta, mas também como campo de reflexão e produção de conhecimentos.
\end{abstract}

\section{Palavras-chave}

Educação popular e saúde. Produção de conhecimento. Pesquisa participativa.

\footnotetext{
1 Esse texto deriva das reflexões construídas coletivamente durante os Painéis Temáticos "Eixo de Pesquisa na Educação Popular em Saúde: desafios atuais e perspectivas" e "EPS, os processos de pesquisa e produção do conhecimento" do II Seminário Temático do Grupo Temático de Educação Popular e Saúde da Associação Brasileira de Saúde Coletiva (GT EPS/ABRASCO), ocorrido nos dias 4 e 5 de fevereiro de 2020, em Parnaíba, Piauí, Brasil.

${ }^{2}$ Doutora em Saúde Coletiva pela Universidade do Estado do Rio de Janeiro, Brasil, com estágio pósdoutoral pelo Centro de Estudos Sociais da Universidade de Coimbra, Portugal; professora associada da Faculdade de Enfermagem da Universidade do Estado do Rio de Janeiro, Brasil; integrante do GT EPS/ABRASCO. E-mail: soacioli@gmail.com.

${ }^{3}$ Doutor em Saúde Coletiva pela Universidade Estadual de Campinas, São Paulo, Brasil; professor titular do Centro de Ciências da Saúde da Universidade Federal do Piauí, Brasil; integrante do GT EPS/ABRASCO. E-mail: jivopedrosa@gmail.com.
} 


\title{
The processes of knowledge production and research in popular education and health $^{4}$
}

Sonia Acioli ${ }^{5}$, José Ivo dos Santos Pedrosa ${ }^{6}$

\begin{abstract}
In this reflection we defend a way of thinking and making the pedagogical practice situated in the historical struggle against the various forms of oppression and the non-recognition of diverse knowledge, especially popular and traditional knowledge. And, the identification of possible paths in the articulation between pedagogical practices from the perspective of popular education and health (PHE) and processes of knowledge and research production that consider the various looks and meanings present and their commitment to the struggles for a good living.Therefore, in addition to talking about methods and methodologies, we recognize the need to articulate our pedagogical practices and PHE policies to research practices that strengthen PHE as a field of action and struggle, but also as a field of reflection and knowledge production.
\end{abstract}

\section{Keywords}

Popular education and health. Knowledge production. Participatory research.

\footnotetext{
${ }^{4}$ This production is based on the collective reflections of the conference panels "Research in Popular Health Education: current challenges and perspectives" and "The Popular Health Education, the research processes and the knowledge production" presented in the II Thematic Seminar of the Thematic Group for Popular Education and Health of the Brazilian Association of Collective Health (Brazilian acronym GT EPS/ABRASCO). It occurred from 4th to 5th February 2000 in Parnaíba, State of Piauí, Brazil.

${ }^{5} \mathrm{PhD}$ in Public Health, State University of Rio de Janeiro, Brazil, with post-doctoral internship at the Center for Social Studies, University of Coimbra, Portugal; associate professor at the Faculty of Nursing, State University of Rio de Janeiro, Brazil; member of GT EPS/ABRASCO. E-mail: soacioli@gmail.com.

${ }^{6} \mathrm{PhD}$ in Collective Health, State University of Campinas, São Paulo, Brazil; full professor at the Health Sciences Center at the Federal University of Piauí, Brazil; member of GT EPS/ABRASCO. E-mail: jivopedrosa@gmail.com.
} 
Para que a Educação Popular e Saúde (EPS) possa ser estratégia de luta e de transformação social é preciso querer recriar saberes e caminhos, lançando mão de conhecimentos e saberes capazes de formular maneiras solidárias de partilhar a vida. E, considerando que as perguntas problematizadoras servem de guia para desvendarmos outros caminhos, o que permeia este texto são questões-guia cujas respostas são continuadamente buscadas junto aos processos nos quais emergiram como questões: Para quem e para que pesquisar? Como têm sido construídas nossas pesquisas? O conhecimento produzido nas práticas de EPS tem sido reconhecido pela academia? Pela população?

À primeira vista o tema dessa discussão revela uma dicotomia entre a produção de conhecimentos e a produção de pesquisas que, é pouco perceptível no mundo da vida, sendo uma separação mais visível nos mundos acadêmico e organizacional. Grosso modo, é possível afirmar que nem sempre o conhecimento que orienta nossas ações resulta de pesquisas tais como as imaginamos, assim como, nem sempre o resultado das pesquisas produz ações que fazem sentido para nossas vidas e, portanto, se a pesquisa é caminho para o conhecimento, existem múltiplas trilhas.

Dessa forma, nosso desafio é refletir sobre as relações entre práticas de EPS e processos de pesquisa e produção de conhecimentos que, em geral, acontecem de modo desarticulado, ou ainda, cujas reflexões ocorrem mais frequentemente de modo isolado.

O campo da EPS reconhece a existência de múltiplos saberes, híbridos, interculturais, sem hierarquias, pois considera que não existe um saber mais importante que outro, e sim que apenas são diferentes (FREIRE, 2000). Tais saberes em diálogo, mediados pela ação pedagógica entre sujeitos, produzem um saber diferente cujo valor é dado pela capacidade em explicar um problema/situação e contribuir para sua superação. Um saber praxiológico que emerge e é incorporado ao real para modificá-lo.

Entendemos a EPS, conforme indicou Eymard Vasconcelos (2001, p. 15), como "um desejo do conhecimento da vida, da pessoa do outro, de um outro popular que separa classes e vidas no Brasil". Podemos falar de muitos modos sobre o que é EPS, mas principalmente, como campo de ação pedagógica e política. Nesse sentido, a EPS:

busca trabalhar pedagogicamente o homem e os grupos envolvidos no processo de participação popular, fomentando formas coletivas de aprendizado e investigação de modo que promova o crescimento da análise crítica sobre a realidade e o aperfeiçoamento das estratégias de luta e enfrentamento. (VASCONCELOS, 2001, p. 15). 
É importante lembrar que, ao falarmos de EPS, estamos falando de práticas que possuem como princípios o diálogo, a problematização, formas partilhadas de construção de conhecimentos e saberes, a busca por emancipação e ação política de transformação social em favor das classes populares e grupos marginalizados e subalternizados.

Esses princípios pressupõem a incorporação de formas de pesquisar dentro de suas práticas. Ou seja, formas de pesquisar que considerem os interesses e saberes dos grupos envolvidos nas investigações e que, principalmente, sejam realizadas em diálogo, e principalmente com todos os envolvidos. Dessa forma, estaria implícita uma correlação inevitável entre EPS, pesquisa e produção de conhecimentos.

Nesse sentido, entendemos a prática pedagógica como ato de pesquisar, como forma de: "criar saberes, conhecimentos, sentidos de vida, visões de mundo, ideologias de futuro, sensibilidades e sociabilidades" (BRANDÃO, 2014, p. 11-12).

Ao mesmo tempo, quando se fala em pesquisa, a imagem que vem aos olhos é de um cientista dentro de um laboratório, cercado de tubos e computadores. Dessa forma, aqueles que não se enquadram nessa figura não são considerados como tal e, o pior, não se autorizam como pesquisadores, embora tenham passado anos e anos desenvolvendo práticas de busca concreta de respostas às questões do cuidado de si e do outro.

No mundo acadêmico, a pesquisa é considerada como o processo de condução ao conhecimento. Processo com filiação teórica a linhas de pesquisa, condições de realização, rigor metodológico, referências teóricas fortes e resultados consistentes, legitimados como verdade científica para os pares e a sociedade com base em testes estatísticos, ou ainda outras formas de legitimação científica aceitas pelo meio acadêmico.

No plano das organizações e instituições de ciência e tecnologia, o conhecimento praxiológico produzido pelo diálogo entre saberes não é classificável no rol de áreas e subáreas de conhecimento humano apresentadas no campo científico e tecnológico. Como resultado, não existe lugar nos editais lançados pelas agências de fomento, os quais são orientados por interesses conjunturais que, em alguns momentos, priorizam pesquisas voltadas para a produção industrial; outras vezes, análises e tendências econômicas; e no momento atual, vivenciamos um contexto em que as ciências sociais e humanas estão relegadas a segundo plano no desenvolvimento científico e tecnológico do país. 
No entanto, esse saber plural, dialogado e compartilhado é conhecimento. No livro História do menino que lia o mundo, no qual Carlos Rodrigues Brandão (2014) conta a história de Paulo Freire, há um trecho que diz:

Dentro de cada um de nós sempre cabe mais um saberzinho. Antes se pensava que tinha uma idade para aprender e depois outra em que a pessoa só servia para trabalhar ou para "ter filhos". Mas hoje sabemos que se pode aprender por toda a vida. Eu sempre posso ser alguém melhor do que já sou. Eu sempre posso aprender com os outros, com os livros, com o mundo. Posso saber melhor o que já sei. E eu sempre posso aprender de novo o que não sei [...]. (BRANDÃO, 2014, p. 50).

Para autores como Gauthier (2012), existe certa distinção entre saber e conhecimento, em que saber é o conhecimento instituído como objeto legítimo de aprendizagem enquanto o conhecimento em si é a ação de aprender ou o fato de ter aprendido. Para o autor, "o conhecimento é mais do lado da potência crítica instituinte [...] aponta para uma ação crítica de quem conhece sobre si mesmo [...] é desterritorializante [...], coloca em crise os saberes já prontos, identificados e seguros" (GAUTHIER, 2012, p. 34).

O conhecimento inerente aos processos de aprendizagem não existe no vácuo. Segundo Bonfleur (2008), sua existência depende da aderência às pessoas enquanto significado por sujeitos cognoscentes. "Um ato de conhecer implica, portanto, a cumplicidade do sujeito que a realiza [...] comparecer com seus sentidos e percepções prévias a fim de incrementá-las ou refazê-las" (BOUFLEUR, 2008, p. 86).

Mas, a dualidade entre pesquisa e produção de conhecimentos e, entre pesquisa como trabalho acadêmico e pesquisa como práxis pedagógica e política no campo da EPS, nos leva a várias indagações: a começar pela clássica questão que Paulo Freire considera fundamental ao se indagar o mundo: por que é assim? Não poderia ser diferente?

Poderíamos iniciar pelas motivações. A pesquisa institucionalizada, ao se deixar absorver completamente pela tecnologia, preocupa-se mais com a aplicabilidade produtiva e financeira de seus resultados em caráter global do que em entender e superar situações, na maioria das vezes, de âmbito local e coletivo que limitam a vivência plena da vida que a pesquisa como prática política e pedagógica tem como intenção. Os seres humanos, nas pesquisas mais duras, não passam de um conjunto de dados que alimentam o universo, a amostra que garante a confiabilidade dos resultados. Em 
pesquisas de natureza qualitativa, que se preocupam com fenômenos inerentes à subjetividade humana, os participantes passam a ser denominados de sujeitos da pesquisa, embora em muitos projetos científicos não passem de fontes de informações para subsidiar a análise.

Considerando pesquisa como um ato pensado, intencional, que requer diálogo entre o real vivido e o real pensado, entre o mundo desejado e o mundo possível; práticas de compartilhamento de ideias, saberes, sentimentos; atos de disposição e vontade de incomodar-se com certezas petrificadas e naturalizadas, qual seria seu lugar na academia e nos movimentos sociais e seus sujeitos?

A academia - espaço político de luta pela hegemonia de produzir determinadas visões de mundo - caracteriza-se, eminentemente, pela disputa de recursos, de projetos, de títulos, de financiamento; disputas que giram em torno da apropriação de recursos de poder simbólicos por parte de seus membros e por recursos políticos, ou seja, o poder de definir prioridades de financiamento, temáticas, problemas por parte das organizações de pesquisa. E nós, pesquisadores vinculados a instituições universitárias, programas de pós-graduação, atuando na docência, na pesquisa e na extensão como encaramos isso? Apesar das universidades terem, ultimamente, se tornado alvo de movimentos que lhe restringem o caráter público, o pensamento e a criatividade, ainda guardam a possibilidade de serem espaços de movimentação dos saberes do mundo e por ainda não serem instituições totais, possibilitam encontros, conhecimentos e relações que se estabelecem nos interstícios, nas dobras, nas fímbrias do instituído.

Por um lado, queremos que o saber popular seja reconhecido pela academia como um saber que apesar de diferente apresenta justificativas, questões e respostas a problemas da sociedade. Por outro lado, as normas e métricas que classificam e mensuram a produção da ciência não fazem sentido para um conhecimento que prima mais pela compreensão da singularidade que pela afirmação de leis gerais. Diante dessa aparente encruzilhada, o significado de pesquisa - assim como o de trabalho acadêmico - passa a ser o de ação política e pedagógica, a qual nos mobilizamos, nos comprometemos e protagonizamos, tendo por motivação, disposição e vontade o diálogo que fazemos como sujeitos no mundo da vida, trazendo como temas de pesquisa problemas que se reproduzem no cotidiano das pessoas.

É interessante resgatar a participação ativa dos departamentos de medicina/saúde comunitária, preventiva e social das universidades na configuração da EPS, que 
consideramos um campo de saber e fazer, por meio dos projetos de extensão universitária.

Na perspectiva da pesquisa como ação política e pedagógica no campo da EPS, é mais importante sua intencionalidade e como os sujeitos participam desse processo desde a definição do que pesquisar até as formas de conduzir, analisar e sistematizar.

Desse modo, considerando a diversidade de práticas e saberes presentes na EPS, é necessário escolher formas de fazer pesquisa que partam do concreto e das experiências cotidianas, que promovam diálogo entre as várias ciências e saberes e que respondam a perguntas concretas. Ou seja, há caminhos de pesquisa que, há muito tempo, dialogam com a EPS. Um diálogo que diz respeito tanto ao referencial teórico quanto a técnicas metodológicas participativas que possibilitem a vivência de processos coletivos de sistematização do diálogo entre os vários olhares que se fazem presentes e expressam formas de construção partilhada de "novos" conhecimentos. Pesquisas que consigam incluir as pessoas motivadas e dispostas (sejam do mundo acadêmico ou não) no processo de construção para além da simples participação na coleta de dados e que incluam o olhar e a lógica da racionalidade do mundo da vida mais que a lógica acadêmica em todas as etapas.

Nesses caminhos, é possível destacar pesquisas com abordagens participativas, tais como pesquisa-ação, pesquisa-ação participativa, sociopoética e a sistematização de experiências são alguns dos exemplos que vão nesse caminho. Lembrando que

A pesquisa-ação tem sua origem na abordagem proposta nos EUA, na década de 1940, com Kurt Lewin (1890-1947). [...] Por sua vez, a chamada pesquisa participante cresceu a partir da década de 1960, principalmente na América Latina, na educação popular, sob a influência de Paulo Freire, Carlos Rodrigues Brandão e outros. (THIOLLENT; COLLETE, 2014, p. 209).

A pesquisa-ação participativa, segundo Nina Wallenstein, diretora do Center for Participatory Research da Universidade do Novo México-EUA e integrante do International Collaboration for Participatory Health Reasearch (ICPHR),

encontra-se firmemente fundamentada na educação de adultos nos EUA com a filosofia de Paulo Freire de "ler o mundo" e seu chamado para ter fé no conhecimento das pessoas para assumir o controle sobre as condições que afetam suas vidas e suas comunidades. (WALLENSTEIN, 2018, p. 10). 
Nesse sentido, a pesquisa seria um processo de co-criação do conhecimento que é prático, colaborativo e empoderador (ICPHR, 2020).

A sociopoética converge várias abordagens como a pedagogia e o teatro do oprimido, a pesquisa-ação, a análise institucional, a socioanálise, os grupos operativos, a pedagogia simbólica e aprendizagem intercultural. Segundo Gauthier (2012, p. 37), “devem confluir na mesma corrente criadora o rigor científico [...] a imaginação poética e artística e a atenção às energias do corpo e da natureza, particularmente presente nos povos que foram colonizados $[\ldots] "$.

A Sistematização de Experiências como proposta nascida na história latinoamericana se aproxima desde seu nascimento com Orlando Farls Borda na década de 1970, à educação popular.

\begin{abstract}
A sistematização de experiências é um exercício intencionado que visa a penetrar na trama "próxima complexa" da experiência e recriar seus saberes mediante um exercício interpretativo de teorização e de apropriação consciente do vivido. Requer um empenho de "curiosidade epistemológica" e supõe "rigor metódico" para converter o saber que provém da experiência, por intermédio de sua problematização, em um saber crítico, em um conhecimento mais profundo. (JARA, 2012, p. 75).
\end{abstract}

Ou seja, há caminhos de pesquisa que dialogam ou podem dialogar com a EPS e que podem ser incorporados e fortalecidos nas nossas práticas de pesquisar e aprender para também sistematizar e fortalecer as práticas de EPS. Para isso, precisamos construir processos coletivos de discussão e sistematização que sejam definidos em conjunto e tragam os contextos e os vários olhares presentes, expressando formas de construção partilhada de "novos" conhecimentos ou de conhecimentos revisitados a partir de outros olhares.

\title{
Referências
}

BOUFLEUR, J. P. Conhecer/conhecimento. In: STRECK, D. R.; REDIN, E.; ZIRKOSKI, J. (org.). Dicionário Paulo Freire. Belo Horizonte: Autêntica, 2008. p. 8586.

BRANDÃO, C. R. História do menino que lia o mundo. São Paulo: Expressão Popular, 2014.

BRANDÃO. C. R. Perguntas, pesquisas. Para quem? Para quê? In: OLIVEIRA, M. W.; SOUZA, F. R. (org.). Processos educativos em práticas sociais: pesquisas em educação. São Carlos: EdUFSCar, 2014. p. 11-12. 
FREIRE, P. Pedagogia da autonomia: saberes necessários à prática educativa. 14. ed. Rio de Janeiro: Paz e Terra, 2000.

GAUTHIER, J. O oco do vento: metodologia da pesquisa sociopoética e estudos transculturais. Curitiba-PR: CRV, 2012

ICPHR - International Collaboration for Participatory Health Research. Position paper 3: impact in participatory health research. 2020. Berlin: ICPHR, 2020.

JARA, O. A sistematização de experiências: prática e teoria para outros mundos possíveis. Brasília, DF: CONTAG, 2012.

THIOLLENT, M.; COLLETE, M. M. Pesquisa-ação, formação de professores e diversidade. Acta Scientiarum: Human and Social Sciences, Maringá, v. 36, n. 2, p. 207-216, jul-dez., 2014.

VASCONCELOS, E. M. Redefinindo as práticas de saúde a partir da educação popular nos serviços de saúde. In: VASCONCELOS, E. M. (org.). A saúde nas palavras e nos gestos: reflexões da rede de educação popular e saúde. São Paulo: Hucitec, 2001. p. 1933.

WALLENSTEIN. N. Prefácio. In: TOLEDO, R. F. et al. (org.). Pesquisa participativa em saúde: vertentes e veredas. São Paulo: Instituto de Saúde, 2018. p. 13-28. 